\title{
Dissociation of Glucagon's Central and Peripheral Hemodynamic Effects: Mechanisms of Reduction and Redistribution of Canine Hindlimb Blood Flow
}

\author{
Andris Kazmers, M.D., Walter M. Whitehouse, JR., M.D., \\ S. Martin Lindenauer, M.D., and James C. Stanley, M.D. \\ Division of Peripheral Vascular Surgery, Department of Surgery, University of Michigan Medical School, \\ Ann Arbor, Michigan 48109
}

Presented at the Annual Meeting of the Association for Academic Surgery, Birmingham, Alabama, November 5-8, 1980

\begin{abstract}
Effects of parenterally administered pharmacologic doses of glucagon on canine hindlimb blood flow were studied. Cardiac output (CO), mean arterial pressure (MAP), total peripheral resistance (TPR), common femoral artery flow (CFAQ), common femoral artery resistance (CFAR), percentage shunt in the hindlimb (AVA\%) determined by ${ }^{99 m} \mathrm{Tc}$ microsphere technique, the volume of hindlimb shunt flow (AVAQ), and the volume of hindlimb nutrient capillary flow (NCQ) were determined at baseline and at 10, 20, and $30 \mathrm{~min}$ during continuous intravenous infusion of $1 \mu \mathrm{g} / \mathrm{kg} / \mathrm{min}$ glucagon $(n=8)$. Blood glucagon and glucose levels were measured at all time periods. Glucagon infusion significantly increased $\mathrm{CO}$ throughout the infusion, while reducing MAP and TPR. Unexpectedly, CFAQ decreased significantly despite the increase in CO. CFAR increased despite the reduction of TPR during glucagon infusion. The reduction of CFAQ was associated with diminished nonshunt hindlimb NCQ and increased AVA\%. Changes in CFAQ, AVA\%, AVAQ, and NCQ did not correlate in a linear fashion with the changes in either blood glucose or glucagon levels by linear regression analysis. Glucagon appeared to cause a major redistribution of peripheral blood flow. Hindlimb arteriolar dilatation was not an effect of this hormone in this experimental model. Glucagon appeared to have a salutary central hemodynamic effect, but was detrimental to canine extremity perfusion.
\end{abstract}

Microcirculatory effects of pharmacologic doses of glucagon were examined in the canine hindlimb. The physiologic effects of this agent on central and splanchnic hemodynamics have been examined extensively, yet few studies have addressed the effects of glucagon on extremity blood flow. The objective of this study was to determine the manner by which parenterally administered glucagon altered canine extremity circulation through naturally occurring precapillary hindlimb arteriovenous anastomoses (AVA) and through the remaining capillary network. Alterations in microcirculatory hindlimb hemodynamics were evaluated in relation to changes in systemic hemodynamics, plasma glucose, and plasma glucagon levels during continuous intravenous infusion of this hormone.

\section{MATERIALS AND METHODS}

Eight fasted adult dogs with a mean weight of $27 \mathrm{~kg}(23-34 \mathrm{~kg})$ were anesthetized with $30 \mathrm{mg} / \mathrm{kg}$ pentobarbital administered intravenously. Supplemental pentobarbital $(5 \mathrm{mg} / \mathrm{kg}$ ) was used as needed, but experimental manipulations were not performed until $40 \mathrm{~min}$ following drug administration.

Animals were intubated and mechanically ventilated, maintaining arterial blood gases within physiologic range. Subjects with acidbase disturbances or hypoxia were not studied. Core temperature was carefully monitored, and all subjects remained normothermic throughout the experiment. The dogs received a $20 \mathrm{cc} / \mathrm{kg}$ bolus of lactated Ringer's solution prior to glucagon ad- 
ministration and a $10 \mathrm{cc} / \mathrm{kg} / \mathrm{min}$ continuous infusion throughout the study.

Carotid arterial and centrally threaded jugular venous catheters were positioned for measurement of systemic arterial and central venous pressure using strain gauge pressure transducers. These data and heart rates were continuously documented using a multichannel recorder. A 7 -french ther- modilution Swan-Ganz catheter was positioned with its tip in the pulmonary artery, and the mean pulmonary capillary wedge pressure (PCWP) was determined intermittently during the study. Cardiac output was measured in triplicate at each experimental period using the thermodilution principle. Total peripheral vascular resistance (TPR), in dyn-sec/ $/ \mathrm{cm}^{5}$, was calculated using the formula

$$
\mathrm{TPR}=\frac{\text { mean arterial pressure }(\mathrm{MAP})-\text { central venous pressure }}{\text { cardiac output }} \times 79.9
$$

Left ventricular stroke work (LVSW) was approximated by the formula

LVSW $=\frac{(\text { MAP }- \text { PCWP })}{\text { Heart Rate }}$

$\times$ cardiac output.

An estimation of external cardiac work (ECW) was calculated at each interval by the formula: $\mathrm{ECW}=\mathrm{MAP} \times \mathrm{CO}$.

A precalibrated nonoccluding square wave electromagnetic flow probe was placed on the common femoral artery for measurement of total common femoral artery flow (CFAQ). Vascular resistance in the common femoral artery (CFR) in dyn$\mathrm{sec} / \mathrm{cm}^{5}$, was calculated disregarding femoral venous pressure using the formula

$$
\mathrm{CFR}=\frac{\text { MAP }}{\mathrm{CFQ} \text { (liters } / \mathrm{min})} \times 79.9 .
$$

A 22-gauge catheter was positioned with its tip at the common femoral artery bifurcation for injection of ${ }^{99 \mathrm{~m}} \mathrm{Tc}$-labeled albumin microspheres. These spheres were $20 \mu \mathrm{m}$ in mean diameter, ranging in size from 10 to $35 \mu \mathrm{m}$, with only $5 \%$ of spheres outside these limits. Spheres were freshly prepared and were discarded if any abnormality in size existed, or if greater than $1 \%$ unlabeled radioactivity was detected by instant thin-layer chromatography. Spheres were sonicated prior to withdrawal into a 1 -cc microsyringe and again prior to injection.
The actual radioactivity of the injectate was determined by measuring the energy of the syringe in a radioisotope dose calibrator both before and after injection. Times of injection, as well as initial and final calibrations, were noted, and the amount injected was corrected for the expected radioactive decay. Residual radioactivity in injection catheters was exceedingly small and was disregarded in subsequent calculations. A nuclear scanner calibrated for measurement of ${ }^{99 m} \mathrm{Tc}$, with a $12.7-\mathrm{cm}$ detector with a straight-bore collimator was placed in a fixed position over the right upper thorax. Microspheres of the size used in this study, when injected into the common femoral artery, are predictably trapped in the hindlimb microcirculation unless they pass through arteriovenous anastomoses [12]. Shunted microspheres passing from the arterial to the venous circulation are predictably trapped in the lung, where their presence is detectable as an increase in radioactivity $[2,12,18$, 23]. The efficacy of the lung as a microsphere trap has been well established $[3,9,19]$. A femoral venous injection of a known dose of microspheres was used as a " $100 \%$ reference shunt" to establish the change in counts per minute $(\Delta \mathrm{cpm})$ over the chest for total shunting (as determined in triplicate by the scanner's digital scaler) per microcurie injected. From 25,000 to 37,500 microspheres were injected at each 
time period in a volume of $\leq 0.1 \mathrm{cc}$. Spheres were injected upstream such that CFQ was not disturbed. The percentage shunt within the common femoral artery circulation was calculated by a standard formula for each intraarterial microsphere injection $[2,12]$.

\% Shunt

$\Delta c p m$ over chest after arterial injection

$$
=\frac{\text { dose of arterial injection }}{\frac{\Delta \text { cpm over chest after venous injection }}{\text { dose of venous injection }}}
$$

$\times 100$.

The actual volume of shunt flow that bypassed the hindlimb capillary network was determined by the formula: hindlimb shunt flow $=\%$ shunt $\times$ total common femoral artery flow $[2,23]$. Nonshunt hindlimb blood flow, which was presumably of a nutritive nature, was calculated by subtracting the volume of shunt flow from total common femoral artery flow $[2,23]$.

The following data were obtained after having achieved a stable baseline: cardiac output, mean arterial pressure, central venous pressure, total peripheral vascular resistance, pulmonary capillary wedge pressure, left ventricular stroke work, heart rate, external cardiac work, total common femoral artery flow, common femoral vascular resistance, percentage hindlimb shunt, as well as the volume of hindlimb shunt flow, and volume of nonshunt nutrient capillary blood flow. Measurements were repeated at 10,20 , and $30 \mathrm{~min}$ during continuous peripheral intravenous infusion of $1 \mu \mathrm{g} / \mathrm{kg} / \mathrm{min}$ glucagon. Blood glucose levels (hexokinase method), and plasma glucagon levels (radioimmunoassay) were also determined at these time intervals [16]. Data were analyzed by paired $t$ and Wilcoxon signed-rank tests. Correlation matrices were performed and Pearson product-moment correlation coefficients determined. Linear regression analysis was performed in standard fashion using the least squares method.

\section{RESULTS}

\section{Central Effects}

Cardiac output rose significantly, and elevations persisted throughout glucagon infusion (Table 1). Both mean arterial pressure and total peripheral vascular resistance fell as cardiac output increased. Mean arterial pressure and total peripheral vascular resistance correlated in a linear fashion at 10, 20, and $30 \mathrm{~min}(P<0.05)$. Left ventricular stroke work decreased significantly, and heart rate rose significantly during glucagon infusion. Cardiac output increases during drug infusion did not correlate significantly with increased heart rates. Despite decreases in left ventricular stroke work, external cardiac work did not change significantly from baseline during drug infusion, but tended to increase at 10 and $30 \mathrm{~min}(0.05<P<0.1)$.

\section{Peripheral Effects}

Despite increases in cardiac output, total common femoral artery flow decreased throughout drug infusion (Table 2). Furthermore, despite decreases in total peripheral vascular resistance, resistance in the common femoral artery circulation increased significantly at 10 and $20 \mathrm{~min}$. The dissociation of cardiac output and femoral flow, as well as the dissociation of total peripheral and hindlimb vascular resistance, were unanticipated findings. Femoral artery flow and resistance correlated inversely and significantly throughout the drug infusion $(P<0.05)$.

In addition to reducing total common femoral artery blood flow, glucagon infusion produced a significant redistribution of hindlimb blood flow (Table 2). Percentage hindlimb shunt rose significantly from a baseline value of $10.5 \pm 6.5 \%$ and was approximately doubled to a value of 20.7 $\pm 12.5 \%$ at $30 \mathrm{~min}$ of drug infusion. The volume of hindlimb shunt flow increased, but the change in absolute shunt flow was not statistically significant by Wilcoxon signed-rank tests, though the change ap- 
TABLE 1

Central EfFects

\begin{tabular}{|c|c|c|c|c|}
\hline & \multirow[b]{2}{*}{ Baseline } & \multicolumn{3}{|c|}{ Glucagon infusion periods } \\
\hline & & $10 \mathrm{~min}$ & $20 \mathrm{~min}$ & $30 \mathrm{~min}$ \\
\hline Cardiac output $(1 / \min )$ & $4.15 \pm 0.37$ & $5.33 \pm 0.63^{* *}$ & $5.15 \pm 0.38^{* * *}$ & $5.23 \pm 0.35^{* *}$ \\
\hline $\begin{array}{l}\text { Mean arterial pressure } \\
\quad(\mathrm{mm} \mathrm{Hg})\end{array}$ & $124 \pm 23$ & $109 \pm 19 * * *$ & $104 \pm 17^{* *}$ & $105 \pm 19 * *$ \\
\hline $\begin{array}{l}\text { Total peripheral resistance } \\
\left(\text { dyn-sec/cm } / \mathrm{cm}^{5}\right)\end{array}$ & $2440 \pm 490$ & $1686 \pm 321^{* *}$ & $1653 \pm 283^{* *}$ & $1660 \pm 395^{* *}$ \\
\hline Left ventricular stroke work & $3.01 \pm 0.37$ & $2.71 \pm 0.47(\mathrm{~ns})$ & $2.40 \pm 0.18^{* *}$ & $2.50 \pm 0.24^{*}$ \\
\hline External cardiac work & $514 \pm 114$ & $584 \pm 132(\mathrm{~ns})$ & $534 \pm 106(\mathrm{~ns})$ & $544 \pm 88(\mathrm{~ns})$ \\
\hline Heart rate & $166 \pm 36$ & $212 \pm 38^{* *}$ & $219 \pm 41^{* * *}$ & $215 \pm 39 * * *$ \\
\hline
\end{tabular}

Note. Data assessed for statistical significance in comparison to baseline values $(n=8)$ using paired $t$ test. Measurements expressed as $\bar{X} \pm 1$ SD.

$$
\begin{gathered}
* P<0.05 \\
* * P<0.01 \\
* * * P<0.001 . \\
\text { ns, not significant. }
\end{gathered}
$$

proached significance at 10 and $30 \mathrm{~min}$ $(0.05<P<0.10)$.

The lack of significant change in absolute shunt flow reflected the fact that total femoral artery flow was decreased as percentage of hindlimb shunt was increased.
Assuming shunt flow to be normally distributed, the increase in shunt flow was significant by a two-tailed paired $t$ test at 10 $\min (P<0.05)$. Shunt flow was inversely related to common femoral artery resist-

\begin{tabular}{|c|c|c|c|c|}
\hline & \multirow[b]{2}{*}{ Baseline } & \multicolumn{3}{|c|}{ Glucagon infusion periods } \\
\hline & & $10 \mathrm{~min}$ & $20 \min$ & $30 \mathrm{~min}$ \\
\hline $\begin{array}{l}\text { Common femoral blood flow } \\
(\mathrm{ml} / \mathrm{min})\end{array}$ & $146 \pm 33$ & $108 \pm 31^{* * *}$ & $110 \pm 29 * *$ & $114 \pm 31^{*}$ \\
\hline $\begin{array}{l}\text { Common femoral resistance } \\
\left(\text { dyn-sec/cm } / \mathrm{cm}^{6}\right)\end{array}$ & $70,181 \pm 17,583$ & $86,977 \pm 28,156^{*}$ & $79,805 \pm 22,532^{*}$ & $77,585 \pm 21,758$ (ns) \\
\hline $\begin{array}{l}\text { Percentage common femoral } \\
\text { artery shunt }\end{array}$ & $10.5 \pm 6.5$ & $18.2 \pm 8.2^{*}$ & $19.6 \pm 10.3^{*}$ & $20.7 \pm 12.5^{* *}$ \\
\hline $\begin{array}{l}\text { Common femoral artery } \\
\text { shunt flow (ml/min) }\end{array}$ & $15.3 \pm 10.5$ & $20.7 \pm 12.1^{*}$ & $22.3 \pm 13.4$ (ns) & $24.6 \pm 19.4(\mathrm{~ns})$ \\
\hline $\begin{array}{l}\text { Common femoral artery } \\
\text { nutrient capillary flow } \\
\text { (ml/min) }\end{array}$ & $131 \pm 31$ & $88.6 \pm 23^{* *}$ & $88.3 \pm 25^{* *}$ & $89.8 \pm 26^{*}$ \\
\hline
\end{tabular}
ance at 10 and $20 \mathrm{~min}(P<0.05)$. While

TABLE 2

Peripheral EFFects

Note. Data assessed for statistical significance in comparison to baseline values $(\mathrm{n}=8)$ using paired $t$ and Wilcoxon signed-rank tests. Measurements expressed as $\bar{X} \pm 1 \mathrm{SD}$.

$* P<0.05$.

${ }^{* *} P<0.01$.

*** $P<0.001$.

ns, not significant. 
percentage shunt and absolute shunt flow were increasing, nutrient capillary hindlimb blood flow decreased significantly, and this occurred despite the improvement in cardiac output during glucagon infusion. Nutrient capillary flow appeared inversely related to common femoral artery resistance at 10,20 , and $30 \mathrm{~min}(P<0.05)$. The changes in total common femoral artery flow, percentage shunt, absolute shunt flow, and hindlimb capillary flow did not correlate in a linear fashion with either changes in glucose or glucagon levels. Other hemodynamic parameters measured in this study did not correlate in a consistent or meaningful way with blood glucagon levels with two exceptions. At $10 \mathrm{~min}$, glucagon levels correlated with heart rate $(P<0.05 ; r=0.82)$. At $20 \mathrm{~min}$, glucagon levels correlated inversely with total peripheral vascular resistance $(P<0.05 ; r=-0.72)$.

Blood glucose and glucagon levels were both altered significantly during the study. Glucose increased from a baseline level of $96 \pm 18 \mathrm{mg} / \mathrm{dl}$ to $183 \pm 26,202 \pm 30$, and $208+41 \mathrm{mg} / \mathrm{dl}$ at 10,20 , and $30 \mathrm{~min}$, respectively $(P<0.001)$. Glucagon levels also increased significantly from baseline values of $213 \pm 148 \mathrm{pg} / \mathrm{ml}$ to $836 \pm 52$, $954 \pm 77$, and $939 \pm 131 \mathrm{pg} / \mathrm{ml}$ at 10,20 , and $30 \mathrm{~min}$, respectively $(P<0.001)$.

\section{DISCUSSION}

Glucagon in pharmacologic doses is known to increase cardiac output, decrease total peripheral resistance, and increase splanchnic blood flow $[5,10,13,15,20]$. The effect of glucagon on extremity blood flow has not been as clearly defined. Previous experiments have found little effect of parenteral glucagon infusion on extremity perfusion in normal human subjects and in a feline experimental model $[1,4,20]$. Other investigators reported that parenteral glucagon administration significantly reduced hindlimb blood flow in the dog $[6,10,11,13]$. To add to the confusion, it had also been reported that direct infusion of glucagon into an isolated perfused canine hindlimb preparation resulted in decreased hindlimb vascular resistance [5]. In the latter study the number of dogs was very small, drug doses were high, and no statistical analysis of the data was provided for evaluation. Interestingly, direct infusion of glucagon into the feline femoral artery did not alter femoral flow but did result in increased splanchnic blood flow [20].

Hemodynamic alterations induced by a vasoactive agent in one regional vascular bed do not necessarily reflect the effects of the drug on systemic hemodynamics. For example, in another study from our laboratory, $1 \mu \mathrm{g} / \mathrm{kg} / \mathrm{min}$ glucagon infusion administered by peripheral vein markedly increased superior mesenteric artery (SMA) blood flow and lowered SMA vascular resistance. In this experiment SMA blood flow comprised a significantly greater proportion of cardiac output during drug infusion indicating that glucagon acted as a selective mesenteric arterial dilator. The effects within the SMA microcirculation were also markedly different than those in the canine hindlimb. Percentage hindlimb shunt was high at baseline, $10.5 \pm 6.5 \%$, and increased significantly during glucagon infusion. In contrast, baseline canine SMA $\%$ shunt was low, $1.79 \pm 0.94 \%$, and did not change significantly during glucagon infusion. Nonshunt capillary flow increased markedly in the gut, but decreased significantly in the hindlimb. It may be postulated that glucagon exerts a specific microcirculatory effect in the canine hindlimb which cannot be explained by simple arteriolar dilatation or constriction. It appears canine hindlimb AVA can respond differently than arterioles when subjected to vasoactive agents, and perhaps are regulated independently of arterioles and capillaries [23].

Reduction in total peripheral resistance and mean arterial pressure with administration of glucagon has been well documented, and is the result of vasodilation in regional beds other than the hindlimb 
$[10,13]$. The increase in cardiac output was not dependent solely on heart rate, and did not correlate with the increase in heart rate during glucagon administration in our study. Other studies have shown that inotropic effects persist despite myocardial pacing, and therefore are not dependent on the positive chronotropic effect of glucagon [5]. The effect of glucagon in lowering left ventricular stroke work must be tempered with the fact that heart rate can increase significantly. This renders the effect of glucagon on myocardial energetics unpredictable, as indicated by the tendency for external cardiac work to increase in our study.

The deleterious effect of pharmacologic doses of glucagon in the extremity circulation may be mediated by the sympathetic nervous system [11]. Glucagon is known to cause release of epinephrine and nonepinephrine from the adrenal medulla [21, 22]. Although experimental administration of catecholamines concomitantly with glucagon does not prevent splanchnic vasodilatation, it is possible that the hindlimb remains responsive to such catecholamines [11]. However, the current study tends to refute such a postulate. The usual response of the canine hindlimb to catecholamines is decreased shunt and nutrient flow [23]. Our study documented an increase in AVA shunting that would not be a likely effect of increased sympathoadrenal activity. Thus, the results of this experiment cannot be explained simply by a glucagon-induced catecholamine effect on the hindlimb microcirculation.

The implications of this study are twofold. First, beneficial central hemodynamic effects of glucagon may not be paralleled by similar effects in the extremity circulation. Second, previous canine metabolic studies examining arteriovenous differences and uptake of various substrates such as glucose or amino acids with glucagon administration should be subject to reexamination. Arteriovenous shunting was never considered in these experiments. For ex- ample, the conclusion that glucagon causes decreased peripheral utilization of glucose, with a high venous glucose concentration and narrow arteriovenous glucose difference across the canine hindlimb, might be the result of hindlimb AVA shunting and not a reflection of the true metabolic role of glucagon.

The dissociation of hindlimb shunt and nutrient capillary blood flow is postulated to be the result of a specific microcirculatory effect of glucagon. The changes in hindlimb hemodynamics are not related in a linear fashion to blood glucose or glucagon levels. It appears the speculation that glucagon might cause arteriovenous shunting is true at least for the canine hindlimb regional vascular bed $[7,8,14,17]$. The peculiar effects of pharmacologic doses of glucagon on canine hindlimb hemodynamics are so dissimilar to the effects of the drug on systemic hemodynamics, that conclusions regarding hindlimb microcirculatory effects are not predictive of the effects on central hemodynamics and should not be extrapolated to other regional vascular beds.

\section{REFERENCES}

1. Bondy, P. K., and Cardillo, L. R. The effect of glucagon on carbohydrate metabolism in normal human beings. J. Clin. Invest. 35: 494, 1956.

2. Cronenwett, J. L., and Lindenauer, S. M. Direct measurement of arteriovenous anastomotic blood flow after lumbar sympathectomy. Surgery 82: 82, 1977.

3. Fan, F. C., Schuessler, G. B., Chen, R. Y. Z., and Chien, S. Determinations of blood flow and shunting of 9- and $15-\mu \mathrm{m}$ spheres in regional beds. Amer. J. Physiol. 237: H25, 1979.

4. Feruglio, F. S., Greco, F., Cesano, L., Colongo, P. G., Sardi, G., and Chiandussi, L. The effects of glucagon on systemic and hepatosplanchnic hemodynamics and on net peripheral and hepatosplanchnic balance of glucose, lactic and pyruvic acids in normal subjects and cirrhotics. Clin. Sci. 30: $43,1965$.

5. Glick, G., Parmley, W. W., Wechsler, A. S., and Sonnenblick, E. H. Glucagon: Its enhancement of cardiac performance in the cat and dog persistance of its inotropic action despite beta-receptor blockade with propranolol. Circ. Res. 22: 789, 1968. 
6. Henneman, D. H. and Shoemaker, W. C. Effect of glucagon and epinephrine on regional metabolism of glucose, pyruvate, lactate, and citrate in normal conscious dogs. Endocrinology 68: 889, 1961.

7. Jensen, H. E. The effect of glucagon on pressure and oxygen saturation of splanchnic venous blood. Amer. J. Dig. Dis. 11: 447, 1966.

8. Jensen, H. E., and Necheles, H. Hemodynamic effects of glucagon in the splanchnic area. Ill Med. J. 130: 49, 1966.

9. Kaihara, S., Van Heerden, P. D., Migita, T., and Wagner, H. N. Jr. Measurement of distribution of cardiac output. J. Appl. Physiol. 25: 696, 1968.

10. Kock, N. G., Tibblin, S., and Schenk, W. G., Jr. Hemodynamic responses to glucagon: An experimental study of central, visceral, and peripheral effects. Ann. Surg. 171: 373, 1970.

11. Kock, N. G., Tibblin, S., and Schenk, W. G., Jr. Modification by glucagon of the splanchnic vascular responses to activation of the sympathicoadrenal system. J. Surg. Res. 1: 12, 1971.

12. Lopez-Majano, V., Rhodes, B. A., and Wagner, H. N., Jr. Arteriovenous shunting in extremities. J. Appl. Physiol. 27: 782, 1969.

13. Madden, J. J., Ludewig, R. M., and Wangensteen, S. L. Effects of glucagon on the splanchnic and the systemic circulation. Amer. J. Surg. 122: $85,1971$.

14. Modlin, I. M., Jaffee, R. M., and Wangensteen, S. L. Effects of glucagon on the splanchnic and the systemic circulation. Amer. J. Surg. 122: $85,1971$.
15. Parmley, W. W., and Sonnenblick, E. H. Glucagon: A new agent in cardiac therapy. Amer. J. Cardiol. 27: 298, 1971.

16. Pek, S., Fajans, S. S., Floyd, J. C., Jr., Knopf, R. F., and Conn, J. W. Failure of sulfonylureas to suppress plasma glucagon in man. Diabetes 21: $216,1972$.

17. Proctor, H. J., Wood, J. J., and Palladino, W. G. The effect of glucagon on hepatic cellular energetics during a low flow state. Surgery 87: 369, 1980.

18. Rhodes, B. A., Rutherford, R. B., Lopez-Majano, V., Greyson, N. D., and Wagner, H. N. Jr. Arteriovenous shunt measurements in extremities. J. Nucl. Med. 13: 357, 1969.

19. Ring, G. C., Blum, A. S., Kurbatov, T., Moss, W. G., and Smith, W. Size of microspheres passing through pulmonary circuit in the dog. Amer. J. Physiol. 200: 1191, 1961.

20. Ross, G. Regional circulatory effects of pancreatic glucagon. Brit. J. Pharmacol. 38: 735, 1970.

21. Sarcione, E. J., Back, N., Sukal, J. E., Mehlman, B., and Knoblock, E. Elevation of plasma epinephrine levels produced by glucagon in vivo. Endocrinology 72: 523, 1963.

22. Scian, L. F., Westermann, C. D., Verdesca, A. S., and Hilton, J. G. Adrenocortical and medullary effects of glucagon. Amer. J. Physiol. 199: 867, 1960.

23. Spence, R. J., Rhodes, B. A., and Wagner, H. N., $\mathrm{Jr}$. Regulation of arteriovenous anastomotic and capillary blood flow in the dog leg. Amer. $J$. Physiol. 222: 226, 1972. 